\title{
COMENTARIOS ACERCA DE ALGUNOS ELEMENTOS DE GESTIÓN TRIBUTARIA, DIGNOS DE SER TENIDOS EN CUENTA EN UNA REFORMA.
}

\section{Por: FLORENTINO RICO CALVANO*}

Una administración tributaria bien estructurada y definida, no puede fallar en la consecución de objetivos, tales como: Maximizar el cumplimiento de las obligaciones tributarias; creación de alto riesgo para el evasor y promoción permanente de mejoramiento de su imagen pública, en cuanto a su integridad, efectividad $y$ eficiencia.

El éxito de los objetivos planteados conduce a la administración tributaria a individualizar e identificar al sujeto pasivo de la obligación tributaria, a determinar la obligación misma, las estrategias adecuadas de recaudación, las acciones pertinentes sobre el incumplimiento de las obligaciones tales como la falta de presentación de declaraciones; acciones correctivas para recuperar las deudas morosas y ajustes mediante auditorías efectivas para detectar la omisión o falsedad en lo declarado.
En América Latina, Chile y Colombia se dirigen hacia este estilo, pero la administración tributaria considerada modelo en este aspecto es la española. Es sumamente importante conocer el estado de la administración tributaria y apreciar con realismo el éxito de los cambios que se piensan introducir; es cierto que éstos no se pueden predecir en forma inmediata y se requiere, en consecuencia, un tiempo razonable para su logro, lo cual depende de las experiencias y habilidades que tengan los gestores de la reforma tributaria.

Se hace necesario definir la ubicación de la administración tributaria en la estructura de la administración pública colombiana en un nivel, preferencialmente de Ministerio, para lo cual se requiere dentro del proceso de la implantación de la reforma una rápida y fluida comunicación con el máximo nivel político del Gobierno, ya que algunas decisiones deben 
tomarse sin dilaciones y con las menores interferencias posibles.

La experiencia en Europa indica que no ha dado buenos resultados el desarrollo de modelos informativos por parte de empresas privadas. Esto sucede cuando se encarga a dichas empresas el diseño global del sistema, el diseño detallado, la programación para computación, los manuales para la operación, la capacitación del usuario y el liderazgo durante la etaoa de implementación.

La falla fundamental radica en otorgar a las empresas privadas la definición del diseño global que contiene el qué hacer y cómo hacerlo, ya que generalmente no cuentan con experiencia en el uso de las técnicas de administración tributaria y utilizan por analogías conceptos aplicables en otros ambientes, generalmente privados, que no son totalmente útiles en una administración de carácter público. Lo antes comentado no es obice para invalidar la contratación de empresas privadas para la realización de estar muy bien definidos previamente.

Es conveniente que la administración de todos los impuestos la realice un único organismo y con un procedimiento general, conociendo particularidades según el impuesto sobre el cual opere en cada caso.

No se puede perder de vista que la sociedad percibe muy rápidamente las incapacidades o debilidades de la administración y esta percepción trae consigo menores recaudos. La incompetencia e inoperancia de la administración puede hacer fracasar cualquier sistema tributario. También se debe considerar la simplificación y normalización de los trámites administrativos, ya que no se han de definir procedimientos $y$ controles que no se han de realizar con plenitud y que solo logran estropear el cumplimiento de las obligaciones por parte del contribuyente. Es mejor tener unos pocos datos actualizados y utilizables que un esquema sofisticado y teóricamente perfecto, pero que en la práctica sea poco aplicable por la falta de datos confiables 0 por la 
complejidad de sus procedimientos.

La política fiscal como instrumento de estabilización económica impone reflexionar seriamente sobre cualquier proyecto de reforma tributaria, como el anunciado por miembros del equipo económico del Gobierno del doctor Ernesto Samper Pizano dentro del Modelo del Salto Social, ya que para financiar macroeconómicamente el plan se necesitan recursos financieros, los cuales podrían ser factibles, de acuerdo al diagnóstico, por la vía impositiva, alternativa que no comparto por cuanto el problema fiscal es de carácter administrativo, por falta de gestión en la recuperación de cartera y controles a la evasión. Es oportuno hacer algunas consideraciones acerca de la posible reforma tributaria anunciada por el Gobierno en los siguientes aspectos: Técnicas o Método para gravar las utilidades de las empresas y las utilidades distribuidas: La mayor dificultad que presenta personalizar las rentas obtenidas a través de sociedades, cuyo capital está representado por valores, consiste en que fácilmente se pueden transmitir, ya que se considera que el factor personal no incide sobre decisiones empresariales por cuanto las personas físicas accionistas titulares no pueden ejercer influencia sobre las decisiones relativas al reparto de dividendos.

En política fiscal a nivel doctrinario se mantienen dos principios en torno a las Sociedades Anónimas: el principio de transparencia fiscal y el principio del ente separado.

La transparencia fiscal está fundamentada en los principios de equidad y de neutralidad. Sostiene que, para los efectos tributarios, debe desconocerse la personalidad de las sociedades anónimas y atribuír las rentas que obtienen a las personas físicas, cualquiera sea el destino que la sociedad dé a esos beneficios.

El principio del ente separado, considera que la personalidad jurídica de las sociedades anónimas trasciende al plano económico, por lo que deben considerarse contribuyentes por las rentas que obtienen, mientras que los dividendos que distribuyen a sus accionistas, constituyen para éstos una renta generada por su inversión en 
acciones, luego las personas físicas que revistan esa condición deben incluirlos en su renta global como rentas producidas por capitales mobiliarios.

Se debe prestar atención a los beneficios destinados para la distribución al integrar la renta de la sociedad, ya que al tributar el impuesto a cargo de la misma, también quedan sometidos a la imposición. La doctrina tributaria ha planteado diversas posiciones que, aceptando 0 no una identidad en la relación accionista- sociedad, da lugar a quienes reconocen esa identidad, sostengan que se trata de rentas distintas. Quienes asumen una posición contraria, consideran que se trata de una única renta y que, en consecuencia, se produce una doble imposición económica, quedando la carga determinada por el nivel de la llamada tasa combinada, que se establece considerando el impuesto tributado y el que debe soportar el accionista sobre los dividendos.

Estas posiciones, han dado lugar a diversas técnicas o métodos de imposición que, tomando en cuenta la integración de los dividendos percibidos por personas físicas en su renta global, aceptan la operación plena de la doble imposición económica, buscan atenuarla a nivel de la sociedad 0 del accionista o la evitan, actuando en cualquiera de los niveles ya indicados.

Las técnicas mencionadas han sido formuladas para definir el tratamiento aplicable a las rentas que obtienen las sociedades anónimas y a las que distribuyen, pero cabe advertir que resultan aplicables a todas las empresas a las que se asigne la condición de contribuyente,

Generalmente en los países en los que predominan las sociedades anónimas cerradas, caso típico de los países latinoamericanos, las técnicas impositivas pueden ejercer diferentes efectos sobre las decisiones empresariales en lo concerniente a la política de dividendos; dicha aplicación puede responder al logro de determinados objetivos; es decir supone operar el impuesto como instrumento de determinadas políticas económicas, para, por ejemplo, obtener una neutralidad relativa sobre las referidas decisiones, restando peso a la 
influencia que el factor tributario pueda ejercer sobre las mismas.

Esto permitiria que las sociedades regulen su política de dividendos en función de sus requerimientos de liquidez. De igual manera, se puede fomentar el ahorro a nivel de las personas físicas y las empresas operando el impuesto como un instrumento de la política de inversiones. EI logro de estos objetivos demanda, para el primer caso, maximizar las distribuciones incluyendo en el impuesto personal un mecanismo que induzca al ahorro $y$, para el segundo caso, maximizar las retenciones de utilidades por parte de las sociedades. También se puede utilizar el impuesto como instrumento de la política de distribución del ingreso, maximizando la distribución de dividendos, de tal forma que la imposición sobre la renta de las personas físicas permita que después de aplicado el impuesto, la estructura de la distribución del ingreso se aproxime a las que las opiniones convencionales consideran deseables u óptimas.

El sistema clásico, o de doble imposición económica, constituye la aplicación estricta del principio del ente separado, es decir, la sociedad tributa sobre el total de sus beneficios impositivos y los accionistas integran los dividendos percibidos en sus renta neta global, operando plenamente la doble imposición económica en las sociedades cerradas. El gravamen a cargo de la sociedad es considerado como un impuesto propio por parte de los accionistas - empresarios que controlan a la sociedad, la mayor carga tributaria a las utilidades distribuidas da lugar a una maximización de las retenciones de beneficios, por eso en aquellos países donde predomina ese tipo de sociedades, el sistema puede ser estratégico para fomentar el ahorro a nivel de las sociedades, al actuar el gravamen como un instrumento de la política de inversiones.

Estas situaciones pueden conducir a que la sociedad recurra a diversas maniobras para realizar distribuciones encubiertas. Cabe señalar que, si la tasa de retención sobre dividendos es de bajo nivel y no se controla la incorporación de los dividendos percibidos a la renta global de los accionistas, puede debilitar el efecto que se 
pretende causar mediante la adopción del sistema.

El sistema de doble tasa atenúa la doble imposición económica, gravando a los beneficios que destina a distribución con una tasa más baja que la que se aplica a los beneficios.

Dentro del esquema de la doble tasa, puede moderarse el nivel de la tasa sobre utilidades retenidas; esto permite alcanzar una neutralidad relativa sobre las decisiones empresariales concernientes al reparto de beneficios, restando importancia a la influencia ejercida por el factor tributario, por lo que cabría esperar un aumento en las distribuciones que permita incrementar la equidad en la asignación de la carga, aún cuando ese efecto no es cuantificable. Si bien el sistema permite asegurar una recaudación significativa complementándolo con un sistema de retención con carácter de pago a cuenta sobre dividendos, técnicamente es sumamente complejo.

Al establecer un tratamiento más favorable para las utilidades canalizadas a distribución, se pueden estructurar beneficios impositivos con la tasa aplicable a dichas utilidades $y$ a las no distribuidas al cumplirse cierto plazo con una tasa adicional, o bien atenerse al destino dado a las utilidades por la Asamblea, estableciendo un plazo de vencimiento que contemple su previa realización. De todas maneras en ambas situaciones se produce un retraso en la recaudación.

En cualquiera de las dos modalidades indicadas, puede ocurrir que, las utilidades que tributaron el impuesto como utilidades retenidas, se distribuyan con posterioridad al pago del impuesto.

Cualquiera sea la modalidad aplicada cuando se distribuyen utilidades retenidas en ejercicios anteriores, se plantea la necesidad de otorgar un crédito por un impuesto tributado en exceso, en consecuencia, además de considerar la relación existente entre los beneficios impositivos y los comerciales, el otorgamiento del crédito suele limitarse a las utilidades atribuibles a un número muy limitado de ejercicios anteriores, uno o dos. 
Finalmente el sistema atenuaría la doble imposición económica, razón por la cual considero es un elemento digno de tenerse en cuenta en el marco de la reforma tributaria que está proponiendo el alto gobierno.
* El autor es Economista, ExDecano de la Facultad de Ciencias Económicas de la Universidad de Cartagena y Profesor Titular de la misma. 